Article

\title{
Exposure to Hantavirus is a Risk Factor Associated with Kidney Diseases in Sri Lanka: A Cross Sectional Study
}

\author{
Yomani D. Sarathkumara ${ }^{1}$ (D), Chandika D. Gamage ${ }^{1}$, Sithumini Lokupathirage ${ }^{2}$, \\ Devinda S. Muthusinghe ${ }^{3}$, Nishantha Nanayakkara ${ }^{4}$, Lishanthe Gunarathne ${ }^{5}$, \\ Kenta Shimizu ${ }^{2} \mathbb{D}$, Yoshimi Tsuda ${ }^{2}$, Jiro Arikawa ${ }^{2}$ and Kumiko Yoshimatsu ${ }^{2,3, * \mathbb{D}}$ \\ 1 Department of Microbiology, Faculty of Medicine, University of Peradeniya, Peradeniya 20400, Sri Lanka \\ 2 Department of Microbiology and Immunology, Faculty of Medicine, Hokkaido University, \\ Sapporo 060-8638, Japan \\ 3 Graduate School of Infectious Diseases, Hokkaido University, Sapporo 060-8638, Japan \\ 4 Nephrology and Transplantation Unit, Teaching Hospital Kandy, Kandy 20000, Sri Lanka \\ 5 Renal Clinic, District Hospital, Girandurukotte 90750, Sri Lanka \\ * Correspondence: yosimatu@med.hokudai.ac.jp; Tel.: +81-11-706-6906
}

Received: 31 May 2019; Accepted: 30 July 2019; Published: 31 July 2019

\begin{abstract}
Chronic kidney disease of unknown etiology ( $\mathrm{CKDu})$ imposes a substantial burden on public health in Sri Lankan agricultural communities. High seroprevalences of hantavirus have been reported in CKDu patients in several locations of Sri Lanka. We carried out a cross-sectional study followed by an unmatched case-control comparison in two geographically distinct areas of Sri Lanka, Girandurukotte (CKDu endemic) and Kandy (CKDu non-endemic) to determine whether exposure to hantaviruses is a potential risk factor in patients with kidney disease. An indirect immunofluorescent antibody assay using two antigens, Thailand orthohantavirus-infected and recombinant N protein-expressing Vero E6 cells, were used for serodiagnosis. Participants' demographic and other socio-economic data were collected through a structured questionnaire. Fifty kidney disease patients and 270 controls from Kandy and 104 kidney disease patients and 242 controls from Girandurukotte were examined. Seropositivities were $50 \%$ and $17.4 \%$ in kidney patients and controls, respectively, in Girandurukotte, and they were $18 \%$ and $7 \%$ in Kandy. The odds of exposure to hantaviruses were higher for kidney disease patients than for controls in both Girandurukotte (OR:3.66, 95\% CI:2.01 to 6.64) and Kandy (OR:2.64, 95\% CI:1.07 to 6.54) in binary logistic regression models. According to statistical analysis, individuals exposed to hantaviruses had a higher risk of developing renal impairment. Therefore, hantavirus infection might be an important risk factor for development of kidney disease in Sri Lanka.
\end{abstract}

Keywords: Thailand orthohantavirus; tropical nephropathy; rodent

\section{Introduction}

Chronic kidney disease (CKD) is a major global public health problem [1]. Diabetes mellitus and hypertension are the most common causes of CKD in developed countries. However, a severe form of CKD that has been reported in individuals without any association of these known risk factors is defined as CKD of unknown etiology (CKDu) [2]. CKDu has emerged as a significant public health crisis in rural agricultural communities in Sri Lanka, among sugarcane farmers in Central American countries, and in some areas of India and Egypt [3]. In Sri Lanka, the number of CKDu patients has been increasing rapidly since the 1990s, mainly in the dry zones of North-Central, Uva and North Western provinces. CKDu prevalence ranges from $15.1 \%$ to $22.9 \%$ in highly prevalent areas [4]. 
Hantaviruses belong to the order Bunyavirales, family Hantaviridae, and genus Orthohantavirus and they are naturally maintained in rodent and other small mammal reservoirs [5]. Several species of hantaviruses cause two important zoonoses: Hemorrhagic fever with renal syndrome (HFRS) in the Old World and hantavirus pulmonary syndrome (HPS) in the New World [6]. In addition to pathogenic viruses, many hantaviruses are known to have low pathogenicity or no pathogenicity in humans. We recently reported high seroprevalence of hantaviruses among CKDu patients in Girandurukotte, one of the CKDu hotspots in Sri Lanka [7]. Preliminary findings suggested that Thailand orthohantavirus (THAIV) or a THAIV-related virus was circulating in this area [8]. THAIV was originally isolated in Thailand in 1985 [9]. However, THAIV is not associated with classic HFRS in Asia, and its pathogenicity in humans has not been determined yet [10-12]. Moreover, the relationship between hantavirus infection and CKDu in Sri Lanka has not been evaluated, as there were no comparative analyses between a CKDu endemic and a non-endemic area in previous studies.

In this study, we conducted a cross-sectional study followed by an unmatched case-control comparison to identify risk factors of exposure to THAIV among renal disease patients and healthy controls in two geographically distinct areas: endemic area (Girandurukotte) and a non-endemic area (Kandy).

\section{Materials and Methods}

\subsection{Selection of Diagnostic Method for CKDu Patient Sera}

We reported that anti-THAIV antibodies were detected from sera collected in Girandurukotte in 2016 and these sera were used to select an appropriate serological diagnostic assay [8]. However, THAIV or a THAIV-related hantavirus has not been isolated in Sri Lanka and thus could not be used as a homologous antigen for serological assays. Recombinant $\mathrm{N}$ protein (rNP) antigens expressed by Escherichia coli (E. coli), baculovirus, and mammalian expression vector (pCAGGS/MCS) were compared in ELISA and an indirect immunofluorescent antibody assay (IFA).

\subsubsection{Virus and Cells}

The THAIV strain Thai749 was propagated in Vero E6 cells (ATCC C1008) [9]. Vero E6 cells were grown in Eagle's minimum essential medium (EMEM; Gibco, Thermo Fisher Scientific, Life Technologies, Waltham, MA, USA) supplemented with 5\% heat-inactivated fetal bovine serum (Biowest, Nuaille, France), penicillin, streptomycin (Sigma Aldrich CO. St Louis, MO, USA), and ITS supplement (insulin-transferrin-selenium, Gibco). High Five cells were grown in Grace's medium (Gibco) supplemented with 10\% heat-inactivated fetal bovine serum (Biowest), penicillin and streptomycin (Sigma Aldrich CO.). Recombinant baculovirus to express rNP of Seoul virus (SEOV) strain SR-11 was inoculated into High Five cells [13].

\subsubsection{Indirect Immunofluorescent Antibody Assay}

The prototype IFA antigen was prepared and used as described previously [14]. Briefly, THAIV or mock-infected Vero E6 cells were trypsinized and cultivated on 24-well glass slides (Matsunami Glass, Osaka, Japan) overnight at $37^{\circ} \mathrm{C}$ in $5 \% \mathrm{CO}_{2}$. Cell sheets on the wells were washed with PBS and then fixed with acetone at room temperature for $10 \mathrm{~min}$ and rinsed with distilled water. After drying, the slides were stored at $-80^{\circ} \mathrm{C}$ until further use. Alexa Fluor 488 -conjugated protein A (Invitrogen, Thermo Fisher Scientific, Life Technologies) was used as the secondary antibody, and IFA tests were performed at a serum dilution of 1:100. Serum showing a clear granular immunofluorescence pattern in the cell cytoplasm of THAIV-infected Vero E6 cells was detected as positive, and a serum specimen showing a non-specific fluorescent profile in both mock and THAIV infected Vero E6 cell antigens were detected as negative. The judgment of the IFA test results was recorded double-blinded by two to four examiners. 


\subsubsection{Preparation of an rNP-Based IFA Antigen}

A recombinant NP antigen of THAIV was originally prepared for serological analyses of rodent sera [15]. The amplified NP gene tagged with ClaI and XhoI recognition sites was cloned into a mammalian expression plasmid vector, $\mathrm{pCAGGS/MCS} \mathrm{following} \mathrm{ClaI} \mathrm{and} \mathrm{XhoI} \mathrm{restriction} \mathrm{treatment} \mathrm{of}$ the NP amplicons and pCAGGS/MCS. Vero E6 cells were transfected with pCAGGS/MCS containing the coding region of THAIV NP by TransIT-LT-1 transfection reagent (Mirus Bio, Madison, WI, USA) according to the manufacturer's instructions. IFA slides containing the rNP-based antigen were prepared as previously described. Transfection efficiency of Vero E6 cells was estimated to be about $5-10 \%$ according to the ratio of rNP-expressing cells detected by monoclonal antibodies E5/G6 directed to NP of Hantaan orthohantavirus (HTNV) described in detail below.

\subsubsection{Mouse Monoclonal Antibodies and Its IFA Profiles}

Mouse monoclonal antibodies directed to HTNV NP, E5/G6 and HTNV envelope glycoproteins (GP), 1G8 antibodies, were used to confirm viral antigens [14,16,17]. Alexa Fluor 488-conjugated goat anti-mouse IgG (Invitrogen) was used as the secondary antibody. Immunofluorescent patterns of NP and GP in both IFA antigens, prototype THAIV, and rNP-based THAIV, were observed.

\subsubsection{ELISA by Using Recombinant NPs}

ELISA was carried out as previously described $[13,18,19]$. Briefly, the entire rNP of SEOV was expressed in High Five cells by baculovirus vector, and the cell lysate was used as the antigen. The cell lysate of High Five cells inoculated with baculovirus lacking polyhedrin gene was used as a negative antigen. The ELISA OD value for the rNP antigen was obtained after subtraction of the ELISA OD value for the negative control antigen. A truncated NP antigen of N-terminal 103 amino acids of HTNV named as HS103 antigen was expressed by an E. coli vector and applied for serological diagnosis for rodents in ELISA and immunochromatography (ICG) $[10,20,21]$. Goat anti-human IgG (H+L) labeled with horseradish peroxidase (Kirkegaard and Perry Laboratories, Inc. (KPL), Gaithersburg, MD, USA) was used as a secondary antibody in ELISA with serum diluted at 1:500.

\subsection{Study Design, Study Population and Sample Size Calculation for the Cross-Sectional Study}

This was a hospital- and community-based cross-sectional study followed by an unmatched case-control comparison. The study was conducted in the Kandy and Badulla Districts (Figure 1a). According to the study objectives, a cross-sectional study was performed to obtain demographic information and to collect blood samples for laboratory analyses (Table 1). The determination of sample size is described in Supplementary Materials S1.

\subsubsection{Hospital-Based Study}

Renal patients were recruited according to the information on patients' clinical record books as diagnosed by the Consultant Nephrologist at Nephrology and Transplantation Unit of Kandy Teaching Hospital (KTH) and residential clinician at the renal clinic, Girandurukotte District hospital (GK DH) according to the standard guidelines [22,23]. Patients clinically diagnosed with a kidney disease residing in the Kandy and Badulla districts and who attended the regular renal clinics in both hospitals were recruited for this study. The sample size from GK DH was estimated, with an approximate prevalence of CKDu of $15 \%$, as reported elsewhere [4]. We estimated the sample sizes for GK DH as 196 and for KTH as 100. Patients (18 years and above) who were clinically diagnosed with kidney disease, who resided in one of the two districts, and who attended the renal clinics conducted by KTH or GK DH were included in this study. Patients of age under 18 years were excluded. 


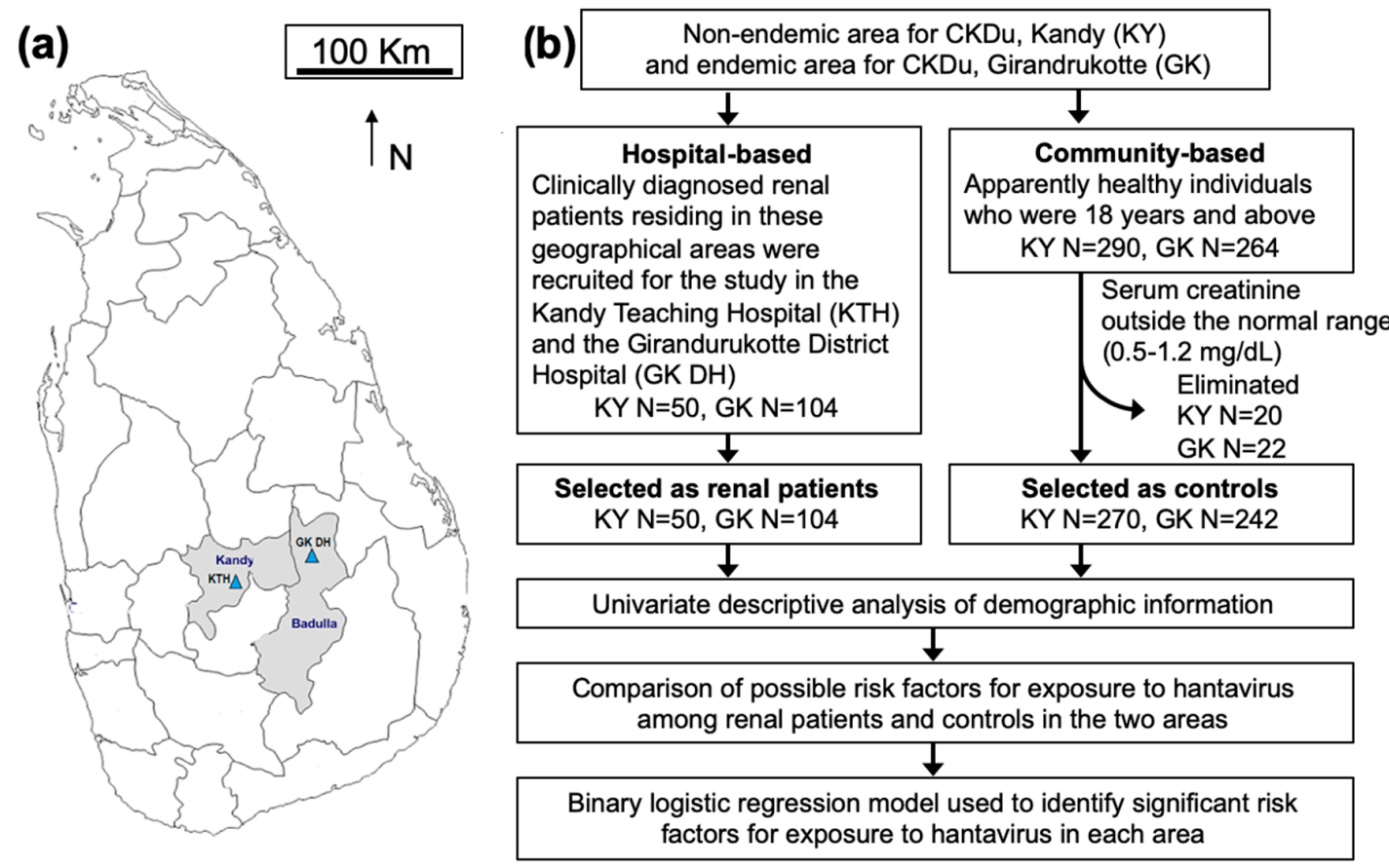

Figure 1. Study area and design. (a) Kandy and Badulla districts of Sri Lanka and the sampling locations. The map shows the locations of Kandy Teaching Hospital (KTH) and Girandurukotte District Hospital (GK DH). (b) Flow chart summarizing the selection process for renal patients and controls and the statistical analyses. Blood and demographic information were collected from individuals. The presence of serum IgG antibodies against hantaviruses was measured and statistically analyzed.

Table 1. Demographic characteristics of the study subjects.

\begin{tabular}{|c|c|c|c|c|c|c|}
\hline Area & Status & Gender & Number & $\begin{array}{l}\text { Age Mean } \\
\text { (SD) }\end{array}$ & $\begin{array}{l}\text { Serum Antibody } \\
\text { Positive to } \\
\text { Hantavirus (\%) }\end{array}$ & $\begin{array}{c}\text { Occupation } \\
\text { Paddy } \\
\text { Farming }\end{array}$ \\
\hline \multirow{6}{*}{ Girandurukotte } & \multirow{3}{*}{ Renal patients } & Male & 70 & $58(12.3)$ & $42(60.0 \%)$ & 65 \\
\hline & & Female & 34 & $60(10.2)$ & $10(29.4 \%)$ & 27 \\
\hline & & Total & 104 & $59(11.7)$ & $52(50.0 \%)$ & 92 \\
\hline & \multirow{3}{*}{ Community } & Male & 98 & 47 (14.8) & $25(25.5 \%)$ & 68 \\
\hline & & Female & 144 & $45(14.0)$ & $17(11.8 \%)$ & 44 \\
\hline & & Total & 242 & $46(14.3)$ & $42(17.4 \%)$ & 112 \\
\hline \multirow{6}{*}{ Kandy } & \multirow{3}{*}{ Renal patients } & Male & 28 & $54(12.6)$ & $7(25.0 \%)$ & 2 \\
\hline & & Female & 22 & $54(11.1)$ & $2(9.1 \%)$ & 1 \\
\hline & & Total & 50 & $54(11.8)$ & $9(18.0 \%)$ & 3 \\
\hline & \multirow{3}{*}{ Community } & Male & 126 & $48(14.5)$ & $10(7.9 \%)$ & 10 \\
\hline & & Female & 144 & $46(13.5)$ & $9(6.3 \%)$ & 3 \\
\hline & & Total & 270 & $47(14.0)$ & $19(7.0 \%)$ & 13 \\
\hline
\end{tabular}

\subsubsection{Community-Based Study}

Medical Office of Health $(\mathrm{MOH})$ areas were randomly selected within the Kandy District. The Regional Director of Health Services for Kandy and Badulla granted permission for collecting blood samples and demographic data from the community in the selected MOH/Public Health Inspector (PHI) areas. People who were 18 years and above, who had no past history or current diagnosis of renal disease, resided in Kandy or Girandurukotte, and who voluntarily provided a blood sample were recruited to the study as controls through the PHIs attached to the selected $\mathrm{MOH}$ areas in two districts. The estimated sample size for Kandy was 385 and that for Girandurukotte was 384 . 


\subsection{Ethical Approval}

Ethical approval for this study was obtained from the Institutional Ethical Review Committee, Faculty of Medicine, University of Peradeniya, Sri Lanka (2016/EC/64) and the Ethical Review Committee of the Graduate School of Medicine, Hokkaido University, Japan (M17-023).

\subsection{Collection of Data and Blood Samples}

Demographic data were collected using a structured questionnaire from both patients and controls. The content of the questionnaire as follows: (1) basic demographic data (age, gender, etc.), (2) family and personal past medical history, (3) occupational/agricultural involvement, and (4) environmental and animal exposure. Blood samples ( $5 \mathrm{~mL}$ from each participant at enrollment) were collected from January 2017 to February 2018 by well-trained medical laboratory technicians by venipuncture in accordance with all safety measures followed by informed consent which was provided in Supplementary Materials S2.

\subsection{Statistical Analysis}

Data obtained from the structured questionnaires from both patients and controls, and the results of laboratory analysis of serum sample were entered into Microsoft Excel ${ }^{\circledR}$. Demographic data were tabulated using Microsoft Excel ${ }^{\circledR}$. All statistical analyses were conducted using Minitab software version 17. Exposure to hantavirus and possible risk factors for that exposure were evaluated using $2 \times 2$ contingency tables and Pearson chi-square $(\chi 2)$ test. A p-value lower than $0.05(p \leq 0.05)$ was considered statistically significant. Fisher's exact test was used when the counts were less than 5 . Odds ratios (ORs) and 95\% confidence intervals (CIs) were calculated in the group exposed to hantaviruses compared with the non-exposed group.

\subsubsection{Univariate Descriptive Analysis}

Univariate descriptive analysis was performed to identify risk factors for exposure to hantaviruses in patients with renal disease and controls residing in Kandy and Girandurukotte.

2.5.2. Comparison of Possible Risk Factors for Exposure to Hantavirus among Seropositive Individuals in the Two Areas

The possible risk factors for exposure to hantavirus were analyzed by $2 \times 2$ contingency tables to evaluate their association with exposure to hantavirus in patients with renal disease and controls residing in Kandy and Girandurukotte.

\subsubsection{Binary Logistic Regression Model}

Binominal logistic regression models with exposure to hantavirus (seropositive) or no exposure to hantavirus (seronegative) as dichotomous response variables were used to identify variables or factors associated with the probability of an individual being infected. We tested whether the set of variables described (Supplementary Materials S3) are able to predict the acquisition of infection. The responses were dichotomized before performing binary logistic regression analysis. We also used a logit link function to separately determine the influence of each of the independent variables. Thus, the analysis prevented independent variables from acting as confounding variables. The ORs were presented in favor of exposure to hantavirus in relation to the reference levels for binominal variables.

\section{Results}

\subsection{Characteristics of Anti-Hantavirus Antibodies in Sera Obtained in Sri Lanka}

\subsubsection{Reactivities in IFA}

As shown in Supplementary Materials S6, rNP-based antigen was successfully detected with anti-NP monoclonal antibodies but not with anti-GP antibodies. In the prototype THAIV antigen, NP 
and GP were detected as fine granular or fibrous structures in cytoplasm. Subsequently, rNP was observed as a defused pattern in the cytoplasm by anti-NP monoclonal antibody and no fluorescence pattern was observed by anti-GP monoclonal antibody in rNP-based antigen. A typical positive pattern by Kandy control serum \#193 and a typical negative pattern by Kandy control serum \#12 are shown in Supplemental data S6. Therefore, samples that showed positive immunofluorescent patterns in both IFA tests. Prototype THAIV and rNP-based-IFA tests, were considered as positive.

\subsubsection{Reactivities in ELISA}

In 2016, we reported a seropositivity rate of 54.5\% in 132 CKDu patients living in Girandurukotte [7]. Serum sampled from these CKDu patients were examined by the aforementioned IFA tests using two antigens and were categorized as seropositive or seronegative. Sixty-one seropositive and 42 seronegative for IFA were subjected to ELISAs using both an HS103 antigen and an rNP-SEOV antigen (Supplementary Materials S7). Differences were observed between the positive and negative groups in the two ELISAs. The HS103 antigen showed high OD values for the negative group, and establishment of a cut-off value was difficult. Therefore, ELISA using the HS103 antigen was not appropriate for serodiagnosis of CKDu patient sera. Even though ELISA using rNP-SEOV expressed in baculovirus vector showed higher specificity than that of HS103 ELISA, it was not considered as an appropriate method for serodiagnosis due to limitations on determining an optimum cut-off point. Therefore, IFA methods with two antigens were used for antibody detection in this study.

\subsection{Demographic Characteristics and Serological Results of the Study Subjects}

As shown in Table 1, there was a high seropositivity rate of 50\% in CKDu patients and a seropositivity rate of $17.4 \%$ in healthy controls in Girandurukotte, similar to the rate in 2016. Strikingly, in Kandy, CKDu non-endemic areas also showed a positive rate as high as $18.9 \%$ in patients with renal disease, while a relatively low positive rate of $7.0 \%$ was found in healthy people. The results of univariate descriptive analysis for each group are shown in Supplementary Materials S4.

\subsection{Comparison of Possible Risk Factors for Exposure to Hantavirus}

As shown in Table 2, in Kandy, several demographic characteristics were considered to be risk factors for exposure to the virus. There was a significant association between the age of 40 years or older and exposure to hantavirus infection $(\chi 2=3.85, p=0.05)$. Moreover, a larger percentage of males were exposed to the virus $\left(\chi^{2}=6.79, p<0.05\right)$. Paddy farming $(\chi 2=11.08, p=0.007)$ and engaging in agricultural activities $(\chi 2=4.95, p=0.030)$ were also identified as risk factors for exposure to hantaviruses, although storing crops at home was not found to be a risk factor. Seeing rodents $(\chi 2=12.58, p<0.001)$ in or around the house was a significant risk factor for exposure to hantaviruses among both renal disease patients and controls in Kandy. Complete data of this analysis is shown in Supplementary Materials S5.

In Girandurukotte, age of 40 years or older $(\chi 2=21.89, p<0.001)$ and male gender $(\chi 2=20.26$, $p<0.001)$ were risk factors for exposure to hantaviruses (Table 2). In addition, paddy farming $(\chi 2=18.30, p<0.001)$ and storing crops at home $(\chi 2=29.32, p<0.001)$ were strongly associated with a higher frequency of exposure to hantavirus. As shown in Table 2, the presence of rodents inside houses or in surrounding areas $(\chi 2=38.42, p<0.001)$ was significantly associated with hantavirus infections in the Girandurukotte area. 
Table 2. Comparison of possible risk factors for exposure to hantavirus in Kandy and Girandurukotte.

\begin{tabular}{|c|c|c|c|c|c|c|c|c|}
\hline \multirow{3}{*}{ Category } & \multicolumn{4}{|c|}{ Kandy } & \multicolumn{4}{|c|}{ Girandurukotte } \\
\hline & \multicolumn{2}{|c|}{ Anti-Hantavirus Antibody } & \multirow{2}{*}{$x^{2}$} & \multirow{2}{*}{$p$-Value } & \multicolumn{2}{|c|}{ Anti-Hantavirus Antibody } & \multirow{2}{*}{$x^{2}$} & \multirow{2}{*}{$p$-Value } \\
\hline & Positive & Negative & & & Positive & Negative & & \\
\hline \multicolumn{9}{|l|}{ Age } \\
\hline \multicolumn{9}{|c|}{ Age category of $\geq 40$ years } \\
\hline Renal patients & 8 & 38 & \multirow{2}{*}{3.85} & \multirow{2}{*}{0.050} & 48 & 47 & \multirow{2}{*}{21.89} & \multirow{2}{*}{$<0.001$} \\
\hline Control & 14 & 166 & & & 32 & 116 & & \\
\hline \multicolumn{9}{|c|}{ Age category of $<40$ years } \\
\hline Renal patients & 1 & 3 & \multirow{2}{*}{2.42} & \multirow{2}{*}{0.235} & 4 & 5 & \multirow{2}{*}{7.99} & \multirow[b]{2}{*}{0.005} \\
\hline Control & 5 & 85 & & & 10 & 84 & & \\
\hline \multirow{2}{*}{\multicolumn{9}{|c|}{$\begin{array}{l}\text { Gender } \\
\text { Female }\end{array}$}} \\
\hline & & & & & & & & \\
\hline Renal patients & 2 & 20 & \multirow{3}{*}{0.25} & \multirow{2}{*}{0.642} & 10 & 24 & \multirow{2}{*}{6.53} & \multirow{2}{*}{0.011} \\
\hline Community & 9 & 135 & & & 17 & 126 & & \\
\hline \multicolumn{8}{|l|}{ Male } & \\
\hline Renal patients & 7 & 21 & & & 42 & 28 & & \\
\hline Community & 10 & 116 & 6.79 & 0.010 & 25 & 73 & 20.3 & $<0.001$ \\
\hline Occupation & & & & & & & & \\
\hline Paddy farming & & & & & & & & \\
\hline Renal patients & 3 & 0 & & & 47 & 45 & & \\
\hline Community & 1 & 12 & 11.08 & 0.007 & 25 & 87 & 18.3 & $<0.001$ \\
\hline Other occupations & & & & & & & & \\
\hline Renal patients & 6 & 41 & & & 5 & 7 & & \\
\hline Community & 18 & 239 & 1.81 & 0.178 & 17 & 113 & 18.3 & 0.009 \\
\hline Storing crop at hou & & & & & & & & \\
\hline Yes & & & & & & & & \\
\hline Renal patients & 2 & 4 & & & 48 & 49 & & \\
\hline Community & 4 & 26 & 1.44 & 0.260 & 28 & 131 & 29.32 & $<0.001$ \\
\hline No & & & & & & & & \\
\hline Renal patients & 7 & 37 & & & 4 & 3 & & \\
\hline Community & 15 & 225 & 4.85 & 0.028 & 14 & 69 & 6.55 & 0.027 \\
\hline Rats seen at home $c$ & dings & & & & & & & \\
\hline Yes & & & & & & & & \\
\hline Renal patients & 8 & 25 & 1258 & $<0,001$ & 45 & 39 & & $<0001$ \\
\hline Community & 12 & 194 & 12.58 & $<0.001$ & 34 & 163 & 38.42 & $<0.001$ \\
\hline No & & & & & & & & \\
\hline Renal patients & 1 & 16 & 039 & 0.535 & 7 & 13 & 231 & 0128 \\
\hline Community & 7 & 57 & 0.39 & 0.335 & 8 & 37 & 2.31 & 0.128 \\
\hline
\end{tabular}

\subsection{Binary Logistic Regression Models}

Binary logistic regression models with exposure as the dichotomous response variable were used to identify statistically significant factors affecting exposure to hantavirus in the areas in this study (Table 3). The binary logistic regression model for Kandy showed that there was a statistically significant association between the response variable and the individual being a renal disease patient (OR: 2.64, 95\% CI: 1.07 to 6.54, $p<0.05$ ). Nevertheless, other interactions between independent variables, except the status of being a renal disease patient or a healthy control, were found to be nonsignificant. The logistic regression model for Girandurukotte showed that there was a strong association between exposure to hantavirus and renal disease in CKDu endemic areas (OR: 3.66, 95\% CI: 2.01 to $6.64, p<0.001$ ). This finding indicated that the odds of an individual having been exposed to hantavirus was three-times higher for renal disease patients than for healthy controls in a CKDu endemic area. Moreover, there was a statistically significant association between seropositivity for hantaviruses and male gender with an OR of 2.79 (95\% CI: 1.58 to 4.95, $p<0.001$ ) in Girandurukotte. In addition, seroconverted individuals $\geq 40$ years of age were found to be at a higher risk of exposure compared to individuals who were less than 40 years of age, although the difference was not significant (OR: $1.92,95 \%$ CI: 0.96 to $3.82, p=0.057$ ). 
Table 3. Results of the binary logistic regression models for Kandy and Girandurukotte for prediction of the risk of an individual being seropositive for hantavirus.

\begin{tabular}{|c|c|c|c|c|c|c|}
\hline \multirow{2}{*}{ Predicted Risk Factors } & \multicolumn{3}{|c|}{ Kandy } & \multicolumn{3}{|c|}{ Girandurukotte } \\
\hline & $x^{2}$ & $p$-Value & OR $(95 \% \mathrm{CI})$ & $x^{2}$ & $p$-Value & OR $(95 \% \mathrm{CI})$ \\
\hline \multicolumn{7}{|l|}{ Status } \\
\hline Renal patient & 4.08 & 0.044 & $2.64(1.07$ to 6.54$)$ & 18.83 & $<0.001$ & $3.66(2.01$ to 6.64$)$ \\
\hline \multicolumn{7}{|l|}{ Age } \\
\hline Age $\geq 40$ years & 0.01 & 0.935 & 1.04 (0.38 to 2.86$)$ & 3.62 & 0.057 & $1.92(0.96$ to 3.82$)$ \\
\hline \multicolumn{7}{|l|}{ Gender } \\
\hline Male & 0.70 & 0.402 & $1.43(0.62$ to 3.31$)$ & 12.88 & $<0.001$ & 2.79 (1.58 to 4.95$)$ \\
\hline \multicolumn{7}{|l|}{ Occupation } \\
\hline Farmer & 1.02 & 0.313 & 2.18 (0.49 to 9.63$)$ & 0 & 0.985 & 0.99 (0.45 to 2.18$)$ \\
\hline \multicolumn{7}{|c|}{ Engaged in agriculture-related activities } \\
\hline Yes & 2.76 & 0.097 & 2.53 (0.88 to 7.27$)$ & 1.41 & 0.235 & $1.82(0.67$ to 4.91$)$ \\
\hline \multicolumn{7}{|l|}{ Store crops at house } \\
\hline Yes & 0.02 & 0.897 & $0.92(0.24$ to 3.47$)$ & 1.30 & 0.255 & $0.65(0.32$ to 1.36$)$ \\
\hline \multicolumn{7}{|c|}{ Sighting rodents at home or surrounding } \\
\hline Yes & 0.06 & 0.446 & $0.67(0.25$ to 1.85$)$ & 2.21 & 0.137 & $1.86(0.81$ to 4.24$)$ \\
\hline \multicolumn{7}{|c|}{ Presence of rodent excreta at home or surrounding } \\
\hline Yes & 0 & 0.982 & $1.01(0.40$ to 2.54$)$ & 1.72 & 0.19 & $0.65(0.34$ to 1.24$)$ \\
\hline
\end{tabular}

\section{Discussion}

This is the first epidemiological study addressing hantavirus infection in renal disease patients in a CKDu endemic and a non-endemic area in Sri Lanka. A higher seroprevalence of hantavirus was found in kidney disease patients than in healthy controls in a CKDu endemic area, as reported in recent studies [7,24].

Girandurukotte, one of the CKDu hotspots, had a greater proportion of exposed individuals than Kandy. The study results provide interesting insights for the hypothesis of exposure to hantavirus as a possible risk factor for the development of CKDu in Sri Lanka [25]. Clinical records showed that 90 of the 104 Girandurukotte renal disease patients had diagnosed CKDu cases according to the 2009 guideline [22]. Significant associations were found between renal disease and hantavirus exposure in both Girandurukotte and Kandy. The majority of seropositive renal disease patients in Girandurukotte were CKDu patients, but none of the renal disease patients in Kandy were diagnosed with CKDu. Furthermore, the nine seropositive renal disease patients in Kandy included seven CKD patients, one end-stage renal disease patient, and one acute kidney injury (AKI) patient. The diagnosis of CKDu in Sri Lanka is made according to guidelines that are solely based on clinical parameters (GFR levels). These results confirm the existence of sporadic hantavirus infection even in Kandy after the first report by Gamage et al. in 2011 [12].

In Girandurukotte, the majority of residents are engaged in agriculture such as paddy farming. In contrast, fewer people are engaged in paddy farming in Kandy than in Girandurukotte. In this study, we showed that age of 40 years or older, male gender, paddy farming, storing crops at home, and witnessing rodents in or surroundings of the house were high-risk factors for hantavirus infection in CKDu endemic areas. Moreover, the presence of anti-hantavirus antibodies was the most significant risk factor among renal disease patients. In Kandy, individuals in the exposed group were older than those in the non-exposure group and were more likely to be male, paddy farmers, and to have sighted rats. However, storing crops at home was not found to be a risk factor for exposure to hantavirus in Kandy. This finding suggested that hantavirus infection in this area might not cause by rodents invading the house and suggests the rationale of lower seroprevalence in females than in males.

Renal disease patients in both areas tended to be older than the controls and there was a larger percentage of males than that in the control groups. However, our results were likely to have been 
affected by biased information provided by the participants with regard to interactions with rodents and their excreta during the survey-based interview. Despite these constraints, this study provides empirical information of exposure to hantavirus as a risk factor for renal disease in a CKDu endemic area.

In 2016, we reported high seropositivities in the CKDu patients living in Girandurukotte [7]. By using their sera, we established a reliable serodiagnostic method for this study. These sera were also applied to ICG by using HS103 antigen as mentioned in a previous report [26]. They showed varied reactivities. Some showed relatively strong bands, whereas others showed faint or no bands (data not shown). Although ICG tests are considered to be the best method for field surveys, they require high affinity and avidity of antigen-antibody binding. In order to develop ICG method specific to Sri Lanka, it is necessary to use an antigen derived from an orthohantavirus specific to Sri Lanka.

In Kandy, which is considered to be a non-endemic area, seroprevalences in renal disease patients and controls (18.0\% and 7.0\%, respectively) were lower than those in Girandurukotte. Furthermore, in this study, the rate of seroprevalence for hantavirus in the apparently healthy population was higher than that reported elsewhere. The seroprevalence of THAIV among healthy controls in Thailand has not been reported yet. However, seroprevalence of $0.4 \%$ (1/260) for THAIV was found in febrile patients in Surin Province of Thailand who were suspected of having leptospirosis and were serologically negative for Leptospira antigens [10]. In Chile, the seroprevalences for Andes orthohantavirus in apparently healthy individuals were reported to be $1.3 \%$ and $1.5 \%$ in rural and urban poor communities, respectively [27]. Similarly, a cross-sectional survey was carried out in an endemic area of the state of Minas Gerais, a peri-urban and rural area in Brazil, to assess the proportion of persons exposed to hantaviruses. Antibody positivity was determined to be $3 \%$ by ELISA using a recombinant antigen of Araraquara orthohantavirus associated with HPS [28], whereas the results of the current study showed a seropositive rate of $17.4 \%$ in controls living in rural agricultural communities of Girandurukotte and a seropositive rate of $7 \%$ in controls living in peri-urban Kandy.

The recent study showed that the innate immune response was activated in CKDu patients, including interferon, inflammasome and triggering receptor expressed in myeloid cell-1 (TREM1) signaling. Transcriptome analysis suggests that viral infections and fluoride or other toxic environmental factors appear to be contributing to the molecular mechanisms underlying the development of CKDu in Sri Lanka [29-31]. However, the causes of CKDu have remained unknown for more than 20 years. The results of this study showed that exposure to hantavirus infection is a possible risk factor underlying renal disease in both endemic and non-endemic areas. Antibodies detected in these individuals were associated with a lack of past clinical symptoms or a medical history of being exposed to hantaviruses, suggesting that infection with THAIV-related hantavirus might be an asymptomatic or a mild infection with nonspecific clinical symptoms at the onset of the disease.

Several studies carried out in Europe has revealed pathogenesis related to mild to moderate forms of kidney damage during several hantavirus infections. In Northern Germany, Dobrava-Belgrade virus (DOBV) infected patients showed a diverse range of mild to moderate clinical manifestations associated with kidney injury [32]. In another study, patients with nephropathia epidemica (NE) often referred as a mild form HFRS caused by Puumala virus exhibited upregulation of biomarkers of inflammation suggested damage in kidney proximal tubule and leukocyte chemotaxis at the onset of $\mathrm{NE}$ in a cohort of patients in a Russian hospital [33]. On the other hand, CKDu in Sri Lanka is known to develop from tubular damage [34,35]. Several Old World hantaviruses have been reported to cause AKI but not HFRS [36]. Furthermore, it has been reported that chronic proteinuria continues even several years after recovery from hantavirus infection [32,37]. Thus, there are similarities between CKDu in Sri Lanka and hantavirus infection. In addition to the epidemiological data obtained in this study, it is necessary to clarify the pathological association between CKDu and hantavirus infection.

Thus, there is a necessity for island-wide sero-epidemiological studies on exposure to hantavirus using both retrospective (renal disease patients) and prospective (nonspecific febrile patients) approaches. Future directions of this study are focused on identifying the reservoir host carrying the THAIV-related hantavirus in these CKDu endemic areas and understanding the dynamics of its transmission to 
humans. The pathological and molecular biological mechanisms underlying the progression of renal damage due to circulating THAIV-related hantaviruses should also be investigated to understand the disease dynamics.

\section{Conclusions}

The results of this study showing a very high seroprevalence of hantavirus in renal disease patients in the studied area that is endemic for CKDu provide an insight into the crucial role of hantavirus in renal disease. Since very few investigators have identified CKDu as a disease with an infectious etiology, communication among research groups worldwide are important to develop internationally accepted definitions for $\mathrm{CKDu}$ in different geographical areas, which will ultimately aid in developing effective means of preventing the disease.

Supplementary Materials: Supplementary materials can be found at http://www.mdpi.com/1999-4915/11/8/700/s1.

Author Contributions: Y.D.S. and D.S.M. collected demographic data and blood samples. Y.D.S. and S.L. conducted serological diagnosis. Y.D.S. and C.D.G. conducted statistical analyses of data and manuscript preparation. Preparation of recombinant IFA antigen slides and serological diagnosis, S.L., D.S.M., K.S., and Y.T.; Collection of renal patient samples in Kandy Teaching Hospital. Discussion with other authors for the interpretation of data, N.N.; Collection of renal patient samples in Girandurukotte District Hospital. Discussion with other authors for the interpretation of data, L.G.; Manuscript preparation and overview, J.A.; Management of all process of the research and manuscript preparation, K.Y.

Funding: This work was partially supported by grants from the JSPS KAKENHI (number 19K10595) and the JSTA Sakura Science Plan (S2017F0228119) that were received by Kumiko Yoshimatsu and a grant provided by the National Science Foundation of Sri Lanka (RPHS/2016/CKDu/06) that was received by Rohana Chandrajith, (Study 03 PI-Chandika D. Gamage), Department of Geology, Faculty of Science, University of Peradeniya, Sri Lanka. A University Research Fellowship (AC/URF/2016/04) received by Yomani D. Sarathkumara for her Master of Philosophy (MPhil) research.

Acknowledgments: We express our appreciation to H.M. Namal Karunarathne, MOH Office, Girandurukotte, for his tremendous support in collecting blood samples from the community in Girandurukotte. We also express our sincere gratitude to Rajitha Abeysekara, Department of Medicine, Faculty of Medicine, University of Peradeniya, for his guidance in the analysis of the results. Furthermore, the authors wish to express their gratitude to staff members of the Department of Microbiology, Faculty of Medicine, University of Peradeniya, for their continuous support and to all study participants for their cooperation.

Conflicts of Interest: The authors declare no conflict of interest.

\section{References}

1. Wang, H.; Naghave, M.; Allen, C.; Barber, R.M.; Bhutta, Z.A.; Carter, A.; Casey, D.C.; Charlson, F.J.; Chen, A.Z.; Coates, M.M.; et al. Global, regional, and national life expectancy, all-cause mortality, and cause-specific mortality for 249 causes of death, 1980-2015: A systematic analysis for the global burden of disease study 2015. Lancet 2016, 388, 1459-1544. [CrossRef]

2. Athuraliya, N.T.; Abeysekera, T.D.; Amerasinghe, P.H.; Kumarasiri, R.; Bandara, P.; Karunaratne, U.; Milton, A.H.; Jones, A.L. Uncertain etiologies of proteinuric-chronic kidney disease in rural Sri Lanka. Kidney Int. 2011, 80, 1212-1221. [CrossRef] [PubMed]

3. Weaver, V.M.; Fadrowski, J.J.; Jaar, B.G. Global dimensions of chronic kidney disease of unknown etiology (CKDU): A modern era environmental and/or occupational nephropathy? BMC Nephrol. 2015, 16, 145. [CrossRef] [PubMed]

4. Rajapakse, S.; Shivanthan, M.C.; Selvarajah, M. Chronic kidney disease of unknown etiology in Sri Lanka. Int. J. Occup. Environ. Health 2016, 22, 259-264. [CrossRef] [PubMed]

5. Plyusnin, A.; Vapalahti, O.; Lundkvist, A. Hantaviruses: Genome structure, expression and evolution. J. Gen. Virol. 1996, 77, 2677-2687. [CrossRef] [PubMed]

6. de Oliveira, R.C.; Guterres, A.; Fernandes, J.; D'Andrea, P.S.; Bonvicino, C.R.; de Lemos, E.R. Hantavirus reservoirs: Current status with an emphasis on data from Brazil. Viruses 2014, 6, 1929-1973. [CrossRef]

7. Gamage, C.D.; Yoshimatsu, K.; Sarathkumara, Y.D.; Thiviyaaluxmi, K.; Nanayakkara, N.; Arikawa, J. Serological evidence of hantavirus infection in girandurukotte, an area endemic for chronic kidney disease of unknown aetiology (CKDU) in Sri Lanka. Int. J. Infect. Dis. 2017, 57, 77-78. [CrossRef] [PubMed] 
8. Yoshimatsu, K.; Gamage, C.D.; Sarathkumara, Y.D.; Kulendiran, T.; Muthusinghe, D.S.; Nanayakkara, N.; Gunarathne, L.; Shimizu, K.; Tsuda, Y.; Arikawa, J. Thailand orthohantavirus infection in patients with chronic kidney disease of unknown aetiology in Sri Lanka. Arch. Virol. 2019, 164, 267-271. [CrossRef]

9. Elwell, M.R.; Ward, G.S.; Tingpalapong, M.; LeDuc, J.W. Serologic evidence of hantaan-like virus in rodents and man in Thailand. Southeast Asian J. Trop. Med. Public Health 1985, 16, 349-354.

10. Pattamadilok, S.; Lee, B.H.; Kumperasart, S.; Yoshimatsu, K.; Okumura, M.; Nakamura, I.; Araki, K.; Khoprasert, Y.; Dangsupa, P.; Panlar, P.; et al. Geographical distribution of hantaviruses in Thailand and potential human health significance of Thailand virus. Am. J. Trop. Med. Hyg. 2006, 75, 994-1002. [CrossRef]

11. Suputthamongkol, Y.; Nitatpattana, N.; Chayakulkeeree, M.; Palabodeewat, S.; Yoksan, S.; Gonzalez, J.P. Hantavirus infection in thailand: First clinical case report. Southeast Asian J. Trop. Med. Public Health 2005, 36, 217-220. [PubMed]

12. Gamage, C.D.; Yasuda, S.P.; Nishio, S.; Kularatne, S.A.; Weerakoon, K.; Rajapakse, J.; Nwafor-Okoli, C.; Lee, R.B.; Obayashi, Y.; Yoshimatsu, K.; et al. Serological evidence of Thailand virus-related hantavirus infection among suspected leptospirosis patients in Kandy, Sri Lanka. Jpn. J. Infect. Dis. 2011, 64, 72-75. [PubMed]

13. Araki, K.; Yoshimatsu, K.; Ogino, M.; Ebihara, H.; Lundkvist, A.; Kariwa, H.; Takashima, I.; Arikawa, J. Truncated hantavirus nucleocapsid proteins for serotyping hantaan, seoul, and dobrava hantavirus infections. J. Clin. Microbiol. 2001, 39, 2397-2404. [CrossRef] [PubMed]

14. Yoshimatsu, K.; Arikawa, J.; Kariwa, H. Application of a recombinant baculovirus expressing hantavirus nucleocapsid protein as a diagnostic antigen in ifa test: Cross reactivities among 3 serotypes of hantavirus which causes hemorrhagic fever with renal syndrome (HFRS). J. Vet. Med. Sci. 1993, 55, 1047-1050. [CrossRef] [PubMed]

15. Lokupathirage, S.M.W.; Muthusinghe, D.S.; Shimizu, K.; Nishigami, K.; Noda, K.; Tsuda, Y.; Sarathkumara, Y.D.; Gunewardana, S.; Arikawa, J.; Gamage, C.D.; et al. Serological evidence of thailand orthohantavirus or antigenically related virus infection among rodents in a chronic kidney disease of unknown etiology (CKDU) endemic area, girandurukotte, Sri Lanka. Vector-borne zoonotic dis. Vector Borne Zoonotic Dis. 2019, in press. [CrossRef] [PubMed]

16. Yoshimatsu, K.; Arikawa, J.; Tamura, M.; Yoshida, R.; Lundkvist, A.; Niklasson, B.; Kariwa, H.; Azuma, I. Characterization of the nucleocapsid protein of hantaan virus strain 76-118 using monoclonal antibodies. J. Gen. Virol. 1996, 77, 695-704. [CrossRef] [PubMed]

17. Arikawa, J.; Schmaljohn, A.L.; Dalrymple, J.M.; Schmaljohn, C.S. Characterization of hantaan virus envelope glycoprotein antigenic determinants defined by monoclonal antibodies. J. Gen. Virol. 1989, 70, 615-624. [CrossRef] [PubMed]

18. Koma, T.; Yoshimatsu, K.; Pini, N.; Safronetz, D.; Taruishi, M.; Levis, S.; Endo, R.; Shimizu, K.; Yasuda, S.P.; Ebihara, H.; et al. Truncated hantavirus nucleocapsid proteins for serotyping sin nombre, andes, and laguna negra hantavirus infections in humans and rodents. J. Clin. Microbiol. 2010, 48, 1635-1642. [CrossRef]

19. Yoshimatsu, K.; Arikawa, J. Serological diagnosis with recombinant $\mathrm{n}$ antigen for hantavirus infection. Virus Res. 2014, 187, 77-83. [CrossRef]

20. Takakura, A.; Goto, K.; Itoh, T.; Yoshimatsu, K.; Takashima, I.; Arikawa, J. Establishment of an enzyme-linked immunosorbent assay for detection of hantavirus antibody of rats using a recombinant of nucleocapsid protein expressed in escherichia coli. Exp. Anim. 2003, 52, 25-30. [CrossRef]

21. Amada, T.; Yoshimatsu, K.; Yasuda, S.P.; Shimizu, K.; Koma, T.; Hayashimoto, N.; Gamage, C.D.; Nishio, S.; Takakura, A.; Arikawa, J. Rapid, whole blood diagnostic test for detecting anti-hantavirus antibody in rats. J. Virol. Methods 2013, 193, 42-49. [CrossRef] [PubMed]

22. Palihawadana, P. Research Programme for Chronic Kidney Disease of Unknown Aetiology in Sri Lanka; Weekly Epidemiological Report Sri Lanka: Peradeniya, Sri Lanka, 2009; Volume 36, pp. 1-4.

23. World Health Organization. Case Definition of Chronic Kidney Disease of Unknown Etiology (CKDU). Available online: http://www.searo.who.int/srilanka/documents/designing_a_step-wise_approach_to_ estimate_the_burden_and_to_understand_the_etiology_of_ckdu_in_srl.pdf (accessed on 27 July 2019).

24. Wijkstrom, J.; Jayasumana, C.; Dassanayake, R.; Priyawardane, N.; Godakanda, N.; Siribaddana, S.; Ring, A.; Hultenby, K.; Soderberg, M.; Elinder, C.G.; et al. Morphological and clinical findings in sri lankan patients with chronic kidney disease of unknown cause (CKDU): Similarities and differences with mesoamerican nephropathy. PLoS ONE 2018, 13, e0193056. [CrossRef] [PubMed] 
25. Gamage, C.D.; Sarathkumara, Y.D. Chronic kidney disease of uncertain etiology in Sri Lanka: Are leptospirosis and hantaviral infection likely causes? Med. Hypotheses 2016, 91, 16-19. [CrossRef] [PubMed]

26. Amada, T.; Yoshimatsu, K.; Koma, T.; Shimizu, K.; Gamage, C.D.; Shiokawa, K.; Nishio, S.; Ahlm, C.; Arikawa, J. Development of an immunochromatography strip test based on truncated nucleocapsid antigens of three representative hantaviruses. Virol. J. 2014, 11, 87. [CrossRef]

27. Munoz-Zanzi, C.; Saavedra, F.; Otth, C.; Domancich, L.; Hott, M.; Padula, P. Serological evidence of hantavirus infection in apparently healthy people from rural and slum communities in southern Chile. Viruses 2015, 7, 2006-2013. [CrossRef] [PubMed]

28. Limongi, J.E.; da Costa, F.C.; Pinto, R.M.; de Oliveira, R.C.; Bragagnolo, C.; Lemos, E.R.; de Paula, M.B.; Pajuaba Neto, A.A.; Ferreira, M.S. Cross-sectional survey of hantavirus infection, Brazil. Emerg. Infect. Dis. 2009, 15, 1981-1983. [CrossRef] [PubMed]

29. Ayala, H.M.; Herath, S.; Kubota, K.; Kawakami, T.; Nagasawa, S.; Motoyama, A.; Weragoda, S.K.; Tushara Chaminda, G.G.; Yatigammana, S.K. Potential risk of drinking water to human health in Sri Lanka. Environ. Forensics 2017, 18, 241-250.

30. Sayanthooran, S.; Gunerathne, L.; Abeysekera, T.D.J.; Magana-Arachchi, D.N. Transcriptome analysis supports viral infection and fluoride toxicity as contributors to chronic kidney disease of unknown etiology (CKDU) in Sri Lanka. Int. Urol. Nephrol. 2018, 50, 1667-1677. [CrossRef]

31. Agampodi, S.B.; Amarasinghe, G.S.; Naotunna, P.; Jayasumana, C.S.; Siribaddana, S.H. Early renal damage among children living in the region of highest burden of chronic kidney disease of unknown etiology (CKDU) in Sri Lanka. BMC Nephrol. 2018, 19, 115. [CrossRef]

32. Meier, M.; Kramer, J.; Jabs, W.J.; Nolte, C.; Hofmann, J.; Kruger, D.H.; Lehnert, H.; Nitschke, M. Proteinuria and the clinical course of dobrava-belgrade hantavirus infection. Nephron Extra 2018, 8, 1-10. [CrossRef]

33. Martynova, E.V.; Maksudova, A.N.; Shakirova, V.G.; Abdulkhakov, S.R.; Khaertynova, I.M.; Anokhin, V.A.; Ivanova, V.V.; Abiola, I.M.; Garanina, E.E.; Tazetdinova, L.G.; et al. Urinary clusterin is upregulated in nephropathia epidemica. Dis. Mark. 2018, 2018, 8658507. [CrossRef] [PubMed]

34. Nanayakkara, S.; Senevirathna, S.T.; Karunaratne, U.; Chandrajith, R.; Harada, K.H.; Hitomi, T.; Watanabe, T.; Abeysekera, T.; Aturaliya, T.N.; Koizumi, A. Evidence of tubular damage in the very early stage of chronic kidney disease of uncertain etiology in the north central province of sri lanka: A cross-sectional study. Environ. Health Prev. Med. 2012, 17, 109-117. [CrossRef] [PubMed]

35. Nanayakkara, S.; Komiya, T.; Ratnatunga, N.; Senevirathna, S.T.; Harada, K.H.; Hitomi, T.; Gobe, G.; Muso, E.; Abeysekera, T.; Koizumi, A. Tubulointerstitial damage as the major pathological lesion in endemic chronic kidney disease among farmers in north central province of Sri Lanka. Environ. Health Prev. Med. 2012, 17, 213-221. [CrossRef] [PubMed]

36. Adams, K.; Jameson, L.; Meigh, R.; Brooks, T. Hantavirus: An infectious cause of acute kidney injury in the UK. BMJ Case Rep. 2014, 2014. [CrossRef] [PubMed]

37. Miettinen, M.H.; Makela, S.M.; Ala-Houhala, I.O.; Huhtala, H.S.; Koobi, T.; Vaheri, A.I.; Pasternack, A.I.; Porsti, I.H.; Mustonen, J.T. Tubular proteinuria and glomerular filtration 6 years after puumala hantavirusinduced acute interstitial nephritis. Nephron Clin. Prac. 2009, 112, c115-c120. [CrossRef] [PubMed]

(C) 2019 by the authors. Licensee MDPI, Basel, Switzerland. This article is an open access article distributed under the terms and conditions of the Creative Commons Attribution (CC BY) license (http://creativecommons.org/licenses/by/4.0/). 